\title{
Is There Room for a Student of Rhetoric in a Giant NSF Grant Project?
}

Sara B. Parks

Iowa State University

Ames, IA

Poroi 10,1 (January 2014)

Keywords: rhetoric of science, praxis, National Science Foundation, broader impacts, grant administration, science communication

The title of this presentation asks is there room for a student of rhetoric in a giant NSF grant project?' This question stems from Leah Ceccarelli's call for rhetoric of science scholars to show what we can contribute to science projects (Ceccarelli, 2013). Most of the articles from POROI's 2013 special issue (Vol. 9, Iss. 1) Inventing the Future: The Rhetorics of Science, Technology, and Medicine, theorize praxis possibilities for rhetoric of science scholars, but few share personal experiences or what Ceccarelli terms "success stories" that provide a roadmap for how to build collaborations.

As a graduate student in the English discipline who has had little to no previous practical experience in scientific, technological, or medical (STM) disciplines, I knew one of the only ways to build enough ethos to gain access to the rhetorical situations I was interested in studying would be to show STM faculty the breadth and depth of knowledge and skills rhetoric study has given me. A year ago, I made the decision to transfer from teaching courses like composition and business writing to be an embedded rhetor in a biorenewables laboratory on campus. My English department teaching assistantship was bought out through the College of Engineering at Iowa State for my work in what is termed "External Engagement and Communications" through the National Science Foundation's Experimental Program to Stimulate Competitive Research (NSF EPSCoR) grant in Iowa. First, I will explain a bit about the grant program itself and then I will explain my role in it by using a question and answer format.

Iowa NSF EPSCoR is a \$20 million, five-year grant to build Iowa's research capacity in renewable energy and energy efficiency. 
It emphasizes multi-institutional and multi- and inter-disciplinary collaborations. It covers all three Iowa Regents Universities and many labs and research projects in many disciplines, including economics, engineering, agronomy, architecture, social science, and others. Its general aim is to "study all elements of the energy valuechain, from natural resource to human consumer." It was originally comprised of four research platforms: wind energy, bioenergy, energy utilization, and energy policy. In practice, a fifth platform has arisen, that of broader impacts, which includes internal evaluation, a diversity taskforce, science, technology, engineering, and math (STEM) education, cyberinfrastructure, workforce development, and my work, external engagement and communications.

\section{How Did a Student of Rhetoric Get Involved with Iowa NSF EPSCoR?}

The grant had funding written into it for the temporary hiring of journalism undergraduates and masters students to work on "communications." A year ago, we convinced grant administration that they should hire someone who could see the grant through to its five-year completion. The administrators were thrilled as they did not know anyone with my varied expertise was even available. Because Iowa State's English department has a tradition of PHD students working outside the department, especially for the purpose of dissertation research, I was not breaking precedent. Now I work with two other EPSCoR staff members, although I am the only graduate student in external engagement and the only external engagement person $100 \%$ funded by the grant.

My role on the project is to be a communicator, in the broadest sense of that term. I write science reporting and general interest articles for the public in a semi-journalistic, semi-public relations style through the Iowa EPSCoR website, which I also helped design and help maintain. I control the Iowa EPSCoR social media. I have helped compose videos, posters, banners, flyers, and other documents that are also part public relations and part technical communication. I mentor undergraduate summer interns from journalism. I am called on to run booths at events and help in event planning. I have helped scientists, engineers, post docs, and graduate students craft public talks and outreach materials, and this summer I was involved with designing STEM education resources. In a very real way, I help tell the story of Iowa NSF EPSCoR to Iowa NSF EPSCoR itself and to others. I am positioned to see all the moving parts of the grant project-a view shared by top administrators. While those administrators are good leaders 
and communicators, their primary expertise lies in their scientific disciplines. In contrast, my training in rhetoric gives me a solid idea of what to do with such a birds-eye view. Rhetoric of science theories about activity systems, boundary objects, even audience analysis and the rhetorical triangle require rhetoric of science scholars to see as much of the whole context as possible. As an embedded rhetor I provide support in my comfort and familiarity with the size and intricacy of the grant project.

\section{What Does a Student of Rhetoric Get in Return for Working in a Lab?}

To start with the gauche concerns, I am a graduate student, and this job does pay more than being a teaching assistant in an English department. I also am beginning to get funding for my research pursuits, and I now think about projects and funding possibilities that would not have otherwise been on my radar. For example, the NSF is interested in funding communication projects. The practical experience, immersion, and hands-on training I am receiving in science journalism, public relations, and event management, have radically changed how I think about composition and communication, and will enrich my future teaching.

I also have scholarly goals that are met by this project. I have great access to all aspects of the grant-funded work across multiple institutions. My dissertation project is still being developed, but it will be at least partly ethnographic and will rely heavily on the network I have built and the trust I have garnered through working for EPSCoR. I intend to have a practical conclusion to my dissertation - a "deliverable" - for the EPSCoR program. The realization that such a deliverable is possible, important, and that my work could have a potential impact on the national program as a whole is exciting. It is a prospect I would have never imagined if I had remained an English TA.

\section{Potential Drawbacks to Being an Embedded Student Rhetoric Scholar.}

I have three potential concerns at this time. I am unsure of the balance I will need to strike when my dissertation research begins in earnest. The boundary between doing communications work and my research into the rhetoric of collaboration and science reporting in large NSF projects is likely to become blurry and I am not sure how I will intellectually or practically separate the two or whether I should even attempt to do so. Secondly, since my research will investigate a problem the NSF acknowledges--persuasive annual 
reporting requirements and their influence on how collaborations are carried out in practice--I am concerned about how my research may be appropriated and used by the NSF. I do not want to provide a blunt instrument or something that could be seen as a quick fix. I am not sure how to impart a rhetorical point of view at the national level without embodying it. Thirdly, I am concerned about leaving teaching for long periods and missing out on graduate teaching experiences. Personally, I have some adjunct work under my belt, so I am less concerned for myself. However, I hesitate to recommend a long-term embedded position to my peers who have less teaching experience.

For a happier conclusion, the STEM faculty and staff I am working with through Iowa NSF EPSCoR are now starting to understand that 1) people exist who study rhetoric of STEM and 2) that there is a scholarly discipline which has the potential to help explain the rhetoric of science, technology, and medicine. I often receive an incredulous "You're from the English department?" when I introduce myself. I use that kairotic moment as an opportunity to remind STEM researchers that the humanities are useful, are more than fine arts, and are involved in meaningcreation. I may not be able to fix all the troubles that come with an unwieldy multi-institutional, multi-disciplinary project, but I can make global sense of communication and collaboration breakdowns where many faculty and staff only see individuals at fault. And I can provide or identify shared objects, ideas, or values that serve to start and restart conversations.

Students of rhetoric seem uniquely suited to understand and use rhetoric knowledge traditions as well as to innovate freely by combining the understandings about communication and persuasion we currently have available to us from many disciplines. Our communication-generalist qualities are perhaps more useful in practice than if we do not innovate through borrowing, or if we valorize only our own disciplinary heritage. As long as the thing we study can be justified as rhetoric then its rhetorical aspects can be investigated for new knowledge making and application.

Copyright @ 2014 Sarah B. Parks

\section{References}

Ceccarelli, Leah. "To whom do we speak? The audiences for scholarship on the rhetoric of science and technology." Poroi 9, Iss. 1(2013): Article 7. 